Jorge Valdebenito, Twitteo, ¿luego resisto? Movilización popular y redes sociales en Chile: La marea roja de Chiloé (2016), Izquierdas, 40, junio 2018:185-201

\title{
Twitteo, ¿luego resisto? Movilización popular y redes sociales en Chile: La marea roja de Chiloé (2016)
}

I tweet, therefore I resist? Popular mobilization and social media in Chile: the case of Chiloe's red tide (2016)

Jorge Valdebenito Allendes*

Resumen: El presente estudio propone explorar la relación entre movilizaciones populares y uso de redes sociales, desde una perspectiva crítica. Para tales efectos se analiza la cobertura que se hizo en Twitter sobre el conflicto de la marea roja de Chiloé (isla al sur de Chile), ocurrido durante abril del año 2016. Los resultados indican que el uso de redes sociales, en el caso de estudio, pasa principalmente por la difusión de información, por sobre la promoción o instrucción a desarrollar acciones políticas concretas.

Palabras clave: Política, tecnología, movilización popular, redes sociales, Internet, Twitter.

Abstract: The present study aims to explore the relation between popular mobilization and social media use, from a critical perspective. In order to achieve this objective, Twitter's coverage about the red tide conflict in Chiloe, an island in the south of Chile, in April 2016 is analyzed. The findings suggest that social media use, in this case study, is mostly directed at sharing information rather than promoting or instructing Twitter users to perform concrete political actions.

Keywords: Politics, technology, popular mobilization, social media, Internet, Twitter.

Recibido: 13 septiembre 2017

Aceptado: 28 octubre 2017

${ }^{*}$ Chileno. Sociólogo, estudiante Doctorado en Estudios Interdisciplinarios, Universidad de Valparaíso, Chile. Becario CONICYT 21171000 (2017-2020). Email: jorge.valdebenito@postgrado.uv.cl. El autor junto con agradecer el apoyo de Patricio Herrera, Andrés Barriga y Rocío Knipp, destaca que todos los errores del documento son de su exclusiva responsabilidad. 
Jorge Valdebenito, Twitteo, ¿luego resisto? Movilización popular y redes sociales en Chile: La marea roja de Chiloé (2016), Izquierdas, 40, junio 2018:185-201

\section{Introducción: Movilización popular y uso de redes sociales, de la Primavera}

\section{Árabe a Chiloé}

Durante los últimos años, principalmente desde los acontecimientos asociados a las Primaveras Árabes ${ }^{1}$, pero no exclusivamente desde $\operatorname{estos}^{2}$, la relación entre movilizaciones políticas y uso de redes sociales en el mundo contemporáneo, ha sido eje de variadas discusiones. El presente estudio propone explorar la relación entre ambas variables, desde una perspectiva crítica, en el contexto chileno contemporáneo ${ }^{3}$. Por crítica, en este contexto, se remite hacia una postura que plantee el escepticismo acerca de la necesidad fundada, según algunos, de articular movilizaciones políticas con el uso de tecnologías de la información y de las comunicaciones (en adelante TICS).

Para tales efectos, se analiza el caso específico de la movilización de la marea roja de Chiloé, protagonizada por pescadores artesanales de la isla de Chiloé, ubicada al sur de Chile. Se desarrolló durante los meses de abril y mayo del año 2016, en el que se firmó acuerdo entre pescadores y gobierno, consistente en el pago de un bono de US\$1.100 a cada familia del lugar. El motivo de las movilizaciones consistió en una serie de acontecimientos vinculados a problemas medioambientales, aludidos a marea roja ${ }^{4}$, que

\footnotetext{
${ }_{1}^{1}$ Para entender el modo en que se desarrolló la producción y diseminación de tweets durante la Primavera Árabe, revisar Gilad Lotan, Erhardt Graeff, Mike Ananny, Devin Gaffney, Ian Pearce y Danah Boyd, The Arab Spring! The revolutions were tweeted: Information flows during the 2011 Tunisian and Egyptian revolutions, International Journal of Communication 5, 2011, 1375-1405. Para obtener una aproximación crítica al estudio de las redes sociales, revisar Christian Fuchs, Social media: A critical Introduction. Londres, Sage, 2014, y propiamente marxista revisar Christian Fuchs, Hacia un estudio marxiano del Internet, Revista Ciencias Sociales 155, 2017, 63-89. Para aproximarse al estudio de la relación entre Twitter y la comunicación en la era contemporánea, desde una perspectiva descriptiva, revisar Dhiraj Murthy, Twitter. Social Communication in the Twitter Age, Cambridge, Polity Press, 2013.

${ }^{2}$ Para aproximarse a las líneas de investigación que vinculan la relación entre movilización social y uso de herramientas digitales de comunicación, revisar Manuel Castells, Comunicación y poder, Madrid, Alianza Editorial, 2009; Clay Shirky, The political power of social media, Foreign Affairs 90:1, 2011; Charles Tilly y Lesley Wood, Los movimientos sociales, 1768-2008 desde sus orígenes a Facebook, Barcelona, Crítica, 2010.

${ }^{3}$ Para aproximarse a los estudios sobre movilización social y popular en Chile, revisar Violeta Glaría, Sujetos colectivos en búsqueda de sustentabilidad pesquera: relatos de los miembros de una comunidad de pescadores artesanales, V región, Chile, Polis 9:27, 2010, 109-127; Viviana Bravo, Neoliberalismo, protesta popular y transición en Chile, 1973-1989, Política y Cultura 37, 2012, 85-112; Alexis Cortés, El movimiento de pobladores chilenos y la población La Victoria: ejemplaridad, movimientos sociales y el derecho a la ciudad, EURE, 2014, 239-260; y Esteban Valenzuela, Francesco Penaglia y Lía Basaure, Acciones colectivas territoriales en Chile 2011-2013: de lo ambiental-reivindicativo al autonomismo regionalista, EURE 42:125, 2016, 225-250.

${ }^{4}$ Para obtener detalles sobre las características generales de las mareas rojas, revisar Felipe Cabello y Henry Godfrey, Florecimiento de algas nocivas (FANs), ecosistemas marinos y la salud humana en la Patagonia chilena, Revista Chilena de Infectología 33:5, Santiago, 2016, p. 559-560.
} 
Jorge Valdebenito, Twitteo, ¿luego resisto? Movilización popular y redes sociales en Chile: La marea roja de Chiloé (2016), Izquierdas, 40, junio 2018:185-201

impactaron directamente sobre el desarrollo de las actividades económicas de los pescadores artesanales del lugar. Estos últimos atribuyeron la responsabilidad de tales problemas a la mala gestión residual de la industria salmonera de la zona, iniciándose un debate científico no resuelto hasta el día de hoy ${ }^{5}$.

A comienzos del mes de mayo, Greenpeace se suma a las discusiones ${ }^{6}$, generando una campaña mediática, que en redes sociales se desarrolló bajo el hashtag de \#ChiloeResiste. Junto a ello, se observa la introducción de nuevos actores en las discusiones, como grupos ambientalistas y de estudiantes universitarios. Estos protagonizan diferentes manifestaciones de apoyo a los pescadores, rechazo a la gestión del gobierno en el conflicto, además de la implementación de la polémica Ley de Pesca en Chile ${ }^{7}$, vista como parte de procesos de acumulación por desposesión en el país ${ }^{8}$. Se generan además interpelaciones a los medios de comunicación tradicionales por no cubrir adecuadamente lo ocurrido. Realizadas en las principales ciudades chilenas, como Concepción, Valparaíso y Santiago, finalizan abruptamente una vez que se firma acuerdo entre gobierno y pescadores de la isla.

El presente estudio se centra en los orígenes de la movilización, dados durante el mes de abril del año 2016, para estudiar la relación que, entre ella, y el uso de redes sociales, se estableció. A su vez, se busca analizar las condiciones que propiciaron el apoyo, desde distintos sectores, a los pescadores movilizados en la isla del sur de Chile. La hipótesis que orienta las pesquisas sostiene que el ciclo de movilización se debe en primer lugar a la agudización de diferentes contradicciones, principalmente sociales, económicas, y ambientales ${ }^{9}$. Sería a partir de ellas, y no al revés, que ciertos actores emplearían, por ejemplo, TICS para realizar acciones de denuncia y/u organización al respecto. Igualmente, la movilización se originó por acciones realizadas por pescadores artesanales de la isla, no familiarizados con el uso de TICS.

\footnotetext{
5 Para obtener mayores detalles sobre lo acontecido en la isla de Chiloé durante las movilizaciones de la marea roja, revisar HispanTV, Chiloé: La vía chilena al subdesarrollo, 2016, recuperado de: https://www.youtube.com/watch?v=-I0tElnLyd8.

6 Greenpeace, Reporte crisis social ambiental en Chiloé: Resumen ejecutivo, 2016, recuperado de: https:/www.salmonexpert.cl/wp-content/uploads/2016/09/322995006-Informe-de-Greenpeace-por-marea-roja -en-Chiloe.pdf.

7 Para profundizar sobre los detalles de la Ley de Pesca en Chile, revisar Matías Guiloff, Ley de pesca: Explicando un regalo regulatorio, Anuario de Derecho Público UDP, 2016, p. 273-296.

8 Para profundizar en las distinciones sobre el concepto de acumulación por desposesión, revisar David Harvey, El nuevo imperialismo: acumulación por desposesión, Buenos Aires, CLACSO, 2005, y Luis De Matheus e Silva, Desposeer para acumular: reflexiones sobre las contradicciones del proceso de modernización neoliberal de la agricultura chilena, Mundo Agrario 17:34, 2016, e007.

9 Por ejemplo, según datos de la Encuesta CASEN 2015, el 70\% de los trabajadores de las ciudades de Ancud, Castro y Quellón reciben un ingreso menor a 296 mil pesos mensuales, 154 mil pesos menos que el promedio nacional. Para mayores detalles revisar Gonzálo Durán y Marco Kremerman, Los bajos salarios de Chile. Análisis de la Encuesta CASEN 2015, Ideas para el buen vivir 10, 2017, 1-8.
} 
Jorge Valdebenito, Twitteo, ¿luego resisto? Movilización popular y redes sociales en Chile: La marea roja de Chiloé (2016), Izquierdas, 40, junio 2018:185-201

\section{Consideración metodológica}

Para el análisis de la información, se delimita a publicaciones realizadas en Twitter, el que posee un diseño configurado para la generación de contenidos de uso público ${ }^{10}$. Siguiendo una lógica de muestreo intencionado ${ }^{11}$, se seleccionan tweets (nombre que reciben las publicaciones en dicha red) que contengan palabras clave de "marea roja" y "Chiloé", publicados durante el período de estudio (abril del año 2016) ${ }^{12}$. Este tipo de muestreo pese a configurarse puramente de acuerdo a criterios fijados por el investigador, permite gran versatilidad en el uso de estrategias de análisis, óptimo para investigaciones exploratorias.

La extracción de los tweets se realiza mediante un scrapper web, Exporter.py ${ }^{13}$, que permite exportarlos, según criterios delimitados por el usuario, a una base de datos en formato .xlsx. La limitación de esta herramienta es que se restringe a contenidos de tipo público. Asimismo, se debe reconocer que sólo se analizará una parte de los tweets publicados en el marco de las discusiones dadas sobre la marea roja de Chiloé. La razón de ello reside en que muchos de ellos son publicados sin usar necesariamente las palabras clave mencionadas, o bien realizados con opciones de privacidad por sus emisores.

La ejecución del scrapper extrajo 409 tweets, ajustados a los criterios de delimitación mencionados. Sobre ellos se realiza un análisis del contenido ${ }^{14}$, siguiendo propuestas de dos tipologías en la materia: i) de usuarios $^{15}$; ii) de mensajes en contextos de movilización política $^{16}$, lo que permite categorizarlos y realizar un análisis estadístico descriptivo ${ }^{17}$ sobre

\footnotetext{
${ }^{10}$ Ello marca una diferencia con otras redes de uso masificado en Chile, como Facebook, orientada a una red limitada de amigos conocidos en el mundo real, o WhatsApp (servicio de mensajería instantánea de carácter privado).

11 Para mayores detalles sobre muestreos, revisar Arredondo, José y Veliz, Mary, Aspectos teóricos sobre los tipos de muestreos, 2009, Repositorio Institucional de la Universidad de Oriente, recuperado: http://ri.bib.udo.edu.ve/bitstream/123456789/594/1/TESIS_MVyJA--\%5B00550\%5D--\%28tc\%29.pdf

12 Es preciso señalar que si se busca exclusivamente tweets con las palabras "marea roja" se encuentra todo tipo de mensajes, algunos de ellos relacionados con la hinchada de la selección de fútbol chilena, conocida coloquialmente con tal nombre. Por otra parte, los tweets publicados únicamente con la palabra "Chiloé" se refieren a todo tipo de acontecimientos relacionados con la isla, desde paseos turísticos, hasta anécdotas de amigos y/o familiares. Sin embargo, todos aquellos que contienen ambas palabras clave durante el período de selección guardan relación con el fenómeno estudiado por esta investigación.

13 Disponible en: https://github.com/Jefferson-Henrique/GetOldTweets-python.

14 Para mayores detalles sobre análisis del contenido, revisar Pablo Cáceres, Análisis de contenido cualitativo: una alternativa metodológica alcanzable, Revista de la Escuela de Psicología 2, 2003, 53-82.

15 Tipología propuesta en el siguiente trabajo: Soledad Puente, Gonzalo Saavedra y Daniela Grassau, Análisis de contenido: Ausencia de valores periodísticos en los medios informativos ciudadanos, Cuadernos de Información 28, 2011, 19-32.

16 Tipología propuesta en el siguiente trabajo: Anamaria Dutceac y Michael Bossetta, A typology of political participation online: How citizens used Twitter to mobilize during the 2015 British general elections, Information, Communication \& Society 20:11, 2017, 1625-1643.
} 
los mismos. Con ello, además de entender los aspectos cualitativos de las publicaciones, se busca caracterizarlos a partir de distinciones cuantitativas. Así, la presentación de resultados se configura siguiendo parámetros del eje de discusiones desarrolladas en torno a usos de Internet y redes sociales, en contextos de movilización política.

La relevancia teórica del estudio es contribuir al entendimiento del desarrollo de conflictos políticos en la era contemporánea, caracterizados por el uso de recursos tecnológicos ${ }^{18}$. Igualmente, desde sus resultados propone explorar si acaso el desarrollo de agendas de trabajo, o pautas de acción digital, contribuiría al quehacer de organizaciones activistas, en distintos ámbitos. Esto último pensando en si, por ejemplo, el uso de TICS les permitiría coordinarse con otros actores, de intereses similares, situados en espacios o territorios diferentes. Con ello podrían eventualmente explorar la realización de acciones políticas colaborativas, que les permitan movilizar reivindicaciones en diferentes contextos, ante una multiplicidad de instancias, como, por ejemplo, además de espacios decisionales nacionales, cortes internacionales de derechos humanos, entre otras.

\section{Consideración conceptual}

El análisis de la información propone tensionar una postura descriptiva ${ }^{19}$ con una crítica $^{20}$. Es posible resumir la primera de ellas desde la máxima de que tanto la tecnología, como Internet y redes sociales, potencia distintas capacidades de los sujetos. Con ello, comunicarse y establecer acciones colectivas a través de Internet con fines políticos reivindicatorios, aumentaría su probabilidad de éxito.

Herramientas como Twitter, significarían apertura de canales de integración social, en que ciertos sectores tradicionalmente excluidos de la población, mediante su uso, podrían formar parte, por ejemplo, de instancias de toma de decisiones. Así, permitirían de paso facilitar la formación de vínculos entre distintos sujetos, al sortear las limitaciones espaciales y temporales de la comunicación cara-a-cara. Prueba de esto último es la

17 Para mayores detalles sobre las características del análisis estadístico descriptivo, revisar Karina Batthyány, Mariana Cabrera, Lorena Alsina, Marianela Bertoni, Paola Mascheroni, Natalia Moreira, Florencia Picasso, Jessica Ramírez y Virginia Rojo, Metodología de la investigación en Ciencias Sociales: Apuntes para un curso inicial, Universidad de la República, 2011.

18 Para obtener mayores detalles al respecto, consultar: Igor Sábada, Acción colectiva y movimientos sociales en las redes digitales. Aspectos históricos y metodológicos, ARBOR 188, 2012, 781-794.

19 Considerando, principalmente, los aportes de: Castells, op. cit., 87-190; Dutceac, op. cit., 1625-1643; Murthy, op. cit., 92-114; Puente, op. cit., 19-32.

20 Considerando, principalmente, los aportes de Fuchs, op. cit., 179-209; Binimelis, Helder, Disputas tecnológicas y diversidad contextual: El poder tecnológico más allá del capitalismo, Primavera Hacker 2016, 2016, recuperado de: https://www.youtube.com/watch?v=59ulsuz-z6M\&t=7s; Feenberg, Andrew, Teoría crítica de la tecnología, Revista CTS 2:5, 2005, 109-123; Mosco, Vincent, La economía política de la comunicación: una actualización diez años después, CIC Cuadernos de Información y Comunicación 11, 2006, 57-79. 
creciente emergencia de formación de lazos de amistad, e incluso amorosos, entre sujetos situados en contextos diferentes, mediante el uso de TICS.

Sin embargo, siguiendo la perspectiva crítica, los medios de comunicación, y la tecnología en general, se distingue un imperativo a reconocerlos, ante todo, como sistemas socio-técnicos. Ello se traduce en que su diseño y funcionamiento no responde a elementos puramente técnicos o ingenieriles, sino que se configuran de acuerdo a intereses de tipo social, económicos, y culturales. De tal modo, estos ejercerían como mediadores de actividades humanas, en distintos ámbitos, como comunicar o conocer.

Internet, desde tal postura, correspondería a una infraestructura tecnológica que posibilitaría la interacción humana, pero ajustada a protocolos que restringen los parámetros en que esta se ejecuta. Dichos protocolos responderían a elementos sociales, económicos y culturales, no puramente técnicos, por tanto, superables o modificables, siendo el aspecto que la visión crítica intenta enfatizar.

Ambas posturas discuten sobre los cuestionamientos acerca de las implicancias sociales, políticas, económicas, culturales, e incluso históricas, asociadas al uso de tecnologías. Por ejemplo, para el caso de las movilizaciones que terminaron con derrocamientos de gobiernos, como Egipto, Túnez y Libia durante las Primaveras Árabes, se formulan distintas interpretaciones. Descriptivamente, se entendería como resultado de coordinación lograda entre diversos actores mediante el uso de TICS. No obstante, críticamente ello correspondería más bien a la conjugación de diferentes contradicciones estructurales, ante las que ciertos actores emplean todo tipo de acción disponible, entre las que se encuentran eventualmente el uso de TICS. Por tanto, si bien no desconocen que estas últimas pueden contribuir en, por ejemplo, acelerar ciertos procesos políticos, se desconfía que se trate de un factor determinante.

El uso de Twitter durante la marea roja de Chiloé: Entre la difusión de noticias

$$
\text { y la emisión de opiniones. }
$$

El volumen de 409 tweets, extraídos por el scrapper, entrega la primera distinción en la materia. Esta guarda relación con que, si se compara lo twitteado en el marco de las Primaveras Árabes ${ }^{21}$, con lo ocurrido en Chiloé, no hay punto de homologación. Aun así, a efectos exploratorios, la observación del fenómeno permite dilucidar el rol asociado del uso de Twitter en contextos de movilización política contemporáneos.

21 Correspondientes a 170 mil tweets para la revolución tunecina, y 230 mil para la egipcia. Revisar Lotan, op. cit., 1375-1405. 
El análisis cualitativo del contenido de los tweets permite identificar tres categorías que agrupan las cuentas de interés, ilustradas en la Figura 1.

a) Ciudadanos/as, correspondientes a 169 cuentas de personas comunes, que publicaron 205 tweets en total. Representan el 59\% de cuentas $(n=169 / 288)$ y $50 \%$ de tweets $(n=205 / 409)$.

b) Medios de prensa o Periodistas, correspondientes a 104 cuentas de medios de prensa, sean tradicionales o alternativos, y de periodistas, afiliados o no a medios, que publicaron 175 tweets en total. Representan el $36 \%$ de cuentas $(n=104 / 288)$ y $43 \%$ de tweets $(n=175 / 409)$.

c) Otros, correspondientes a 15 cuentas de organismos públicos, empresas, centros de investigación, entre otros, que publicaron 29 tweets en total. Representan el $5 \%$ de cuentas $(\mathrm{n}=15 / 288)$ y $7 \%$ de tweets $(\mathrm{n}=29 / 409)$.

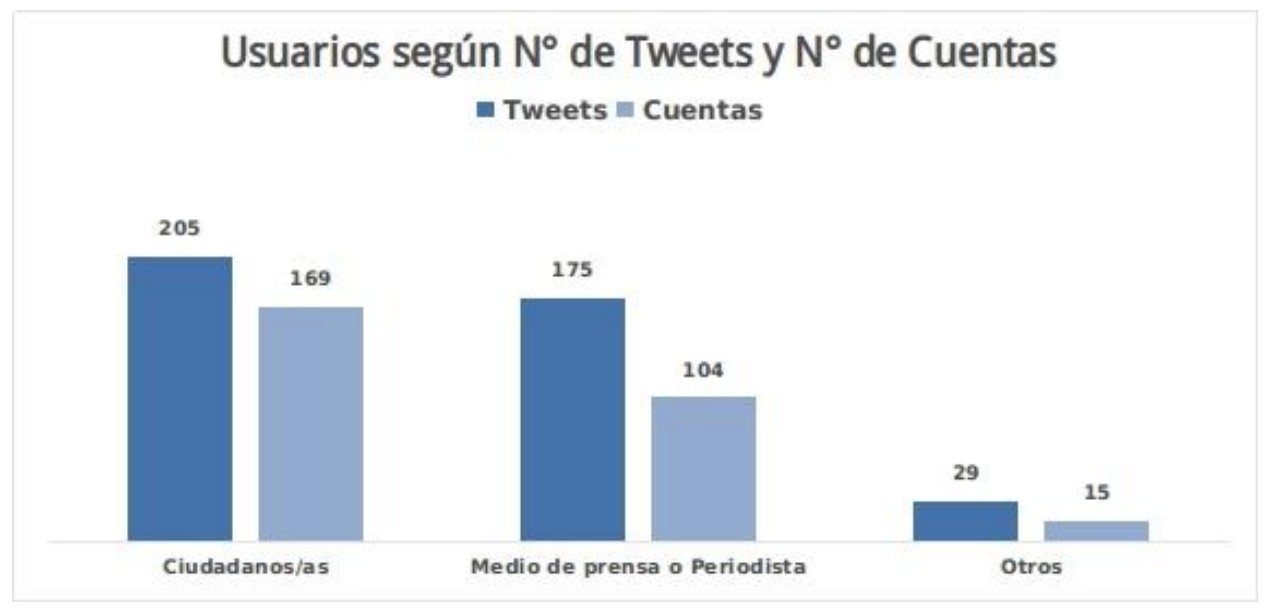

(Figura 1: Usuarios según $\mathrm{N}^{\circ}$ de tweets y $\mathrm{N}^{\circ}$ de Cuentas. Elaboración propia).

\section{Opinión y colaboración informativa}

Al seguir la primera tipología de mensajes ${ }^{22}$, que diferencia el tipo de contenidos según i) opiniones, ii) denuncias, iii) testigos, y iv) colaboraciones informativas, para efectos de análisis se han agrupado las tres primeras categorías. Esto se debe a dos razones. La primera, corresponde a que estas son transversales al contenido de los tweets. La segunda, por su parte, consiste en que dividirlas reduciría estadísticamente su peso en la muestra.

Así, opiniones y/o denuncias se caracterizan por contener dictámenes o juicios sobre un tema, denuncias de hechos que se considera poseen valor noticioso, o divulgación de 
acontecimientos en que el emisor ha tenido directa participación. Estas no se realizan, según los autores, siguiendo valores periodísticos en la publicación de contenidos. Constituyen el 30\% $(\mathrm{n}=122 / 409)$ del total de tweets de estudio, y fueron publicados en un $98 \%(n=120 / 122)$ por cuentas de ciudadanos/as. El 66\% $(n=80 / 122)$ de ellas contienen interpelaciones directas al gobierno, medios de prensa, y empresas asociadas a la industria salmonera, por protagonizar y/o encubrir acontecimientos vinculados a la supuesta marea roja. La distribución se ilustra en la Figura 2.

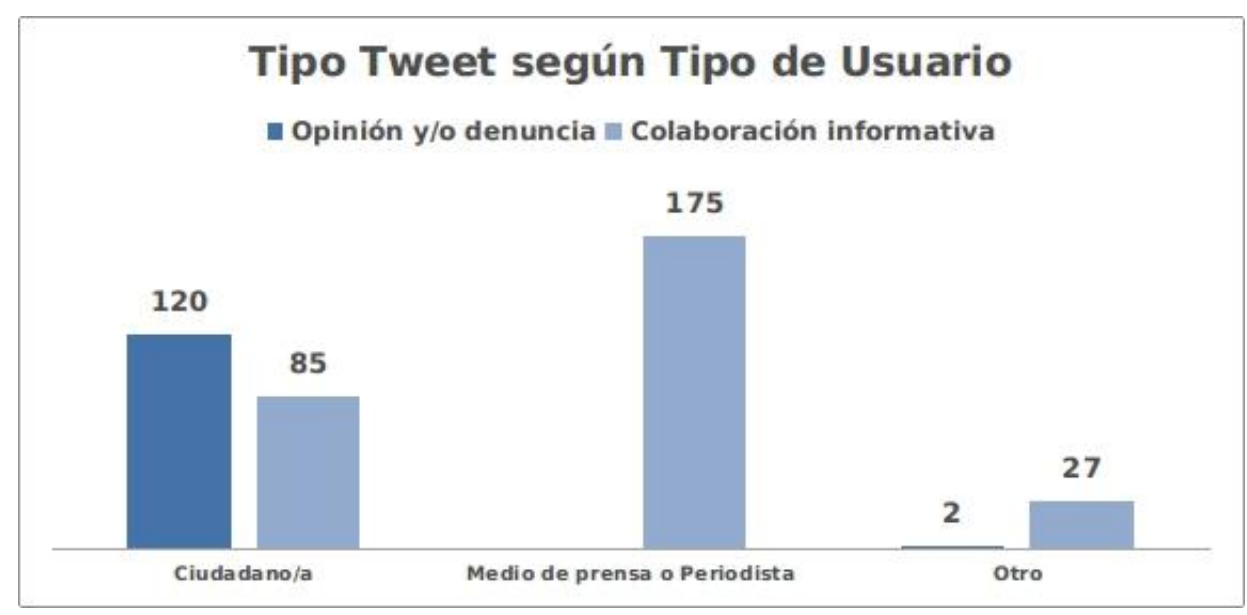

(Figura 2: Tweets según tipología usuarios y tipo de cuenta. Elaboración propia).

Las colaboraciones informativas se caracterizan por el ideal de mostrar objetivamente los hechos, y no contener opiniones y/o juicios de valor sobre ellos. Representan el $70 \%$ $(\mathrm{n}=287 / 409)$ del total de tweets de la muestra, el 100\% $(\mathrm{n}=175 / 175)$ de publicaciones de Medios de prensa y/o Periodistas, 41\% ( $\mathrm{n}=85 / 205)$ de tweets de Ciudadanos/as, y $93 \%$ $(\mathrm{n}=27 / 29)$ de Otros. Sobre estos últimos, cabe destacar que se trata principalmente de cuentas asociadas a organismos públicos, parlamentarios de la zona, y la Armada, y generan sus propias entradas noticiosas sobre el desastre y sus consecuencias.

En resumen, la mayoría de los tweets analizados en el estudio corresponden a publicaciones informativas, siendo este el principal rol asignado, preliminarmente, al uso de la red en el contexto de la movilización estudiada. Ello marca una diferencia respecto de las investigaciones que destacan el rol de las TICS en contextos de agitación política, como las Primaveras Árabes, en cuanto a su contribución a la generación de acciones concretas. Ello constituye el eje de los análisis de la siguiente sección ${ }^{23}$.

${ }^{23}$ La colaboración informativa realizada desde cuentas de usuarios comunes de Twitter, se puede entender, desde lo que señala Pierre Bourdieu, como violencia simbólica. En tal sentido, un actor específico, los medios 


\section{Difusión de información y llamado a la acción}

La segunda tipología empleada, se orienta a distinguir el contenido del tweet de acuerdo a si busca organizar y/o promover acciones políticas, o si se restringe a difundir información ${ }^{24}$. En tal sentido, enfatiza en diferenciar que la promoción de acciones políticas debe ser concreta y detallada, debiendo especificar, por ejemplo, momentos y lugares en que estas se desarrollarán. Mensajes que promuevan en abstracto la acción política, como indicaciones del tipo "debemos luchar contra el Gobierno", o "debemos hacer respetar nuestros derechos”, etc., no caben en tal categoría. Estos son asumidos como informaciones, debido a que no promueven la realización de una acción política bien detallada.

A su vez, esta tipología busca igualmente diferenciar material original y compartido, o retwitteado. Considera que ello es relevante para conocer los mensajes que adquieren finalmente difusión o promoción en el ciberespacio, identificando igualmente las cuentas que los generan y/o comparten. Sin embargo, esta distinción se ha dejado fuera del análisis y categorización de los tweets. Ello se debe a que en este estudio se intenta dilucidar el rol de los mensajes en contextos de movilización política, independiente de si se trata de contenido original o no. La tipología, con todo, se configura a partir de cuatro categorías:

i. Información, correspondiente a contenido original que no llama a la movilización.

ii. Difusión, vinculado a contenido compartido que no llama a la movilización.

iii. Promoción, relacionado a contenido compartido que llama a la movilización.

iv. Instrucción, asociado a contenido original que llama a la movilización.

En consideración de lo anterior, se han agrupado las categorías de "información" y "difusión" por una parte, y de "promoción" e "instrucción" por otra. Los resultados se ilustran en la Figura 3.

de prensa, marcaría la pauta de comportamiento a seguir en Twitter. Al respecto, Jürgen Habermas señala que la ilusión inclusiva del espacio público, refleja en la práctica distintas dinámicas de exclusión presentes en la sociedad. Twitter, así como Internet, entendidos como espacios de participación política, expresarían tales dinámicas. Desde los análisis de las Primaveras Árabes, se indica que redes como Twitter, promoverían y abrirían canales de participación política. Sin embargo, en la práctica quedarían restringidos a la difusión de información, por sobre la organización de acciones políticas concretas. Revisar Bourdieu, Pierre, Razones prácticas. Sobre la teoría de la acción, Barcelona, Anagrama, 1997; Habermas, Jürgen, "The public sphere: An encyclopedia article", Meenashki Durham, y Douglas Kellner (eds.), Media and Cultural Studies: Keyworks, Wiley-Blackwell, 2012, 75-79; Fuchs, op. cit., 181-189; y Mosco, op. cit., 57-79.

${ }^{24}$ Dutceac, op. cit., 1625-1643. 


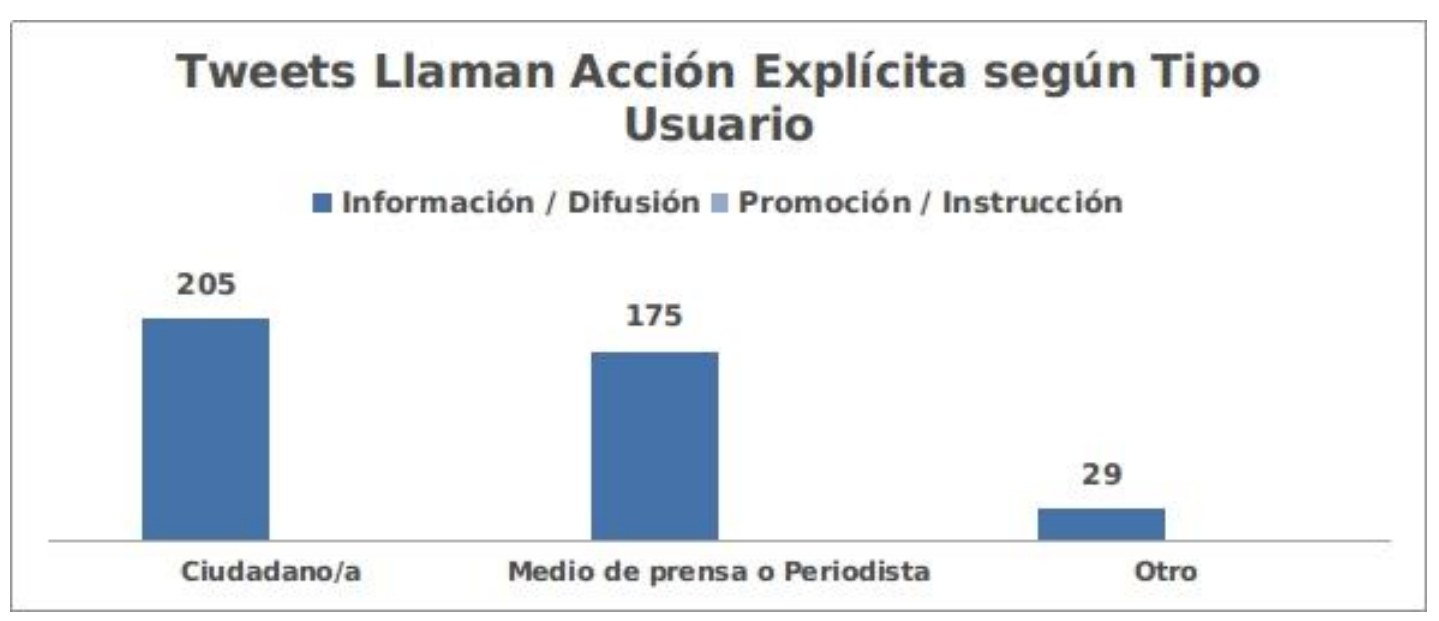

(Figura 3: Tweets según tipología de mensajes y tipo de cuenta. Elaboración propia).

Asumiendo las limitaciones de la muestra, el 100\% del total de los tweets $(\mathrm{n}=409)$ analizados corresponden a difusión de distintos tipos de informaciones, es decir, ninguno de ellos contiene llamados explícitos a la movilización política. Ello puede deberse a que la muestra fue constituida en base a palabras clave, donde no necesariamente coincidieron los tweets que contenían llamados explícitos a la movilización. También debe tenerse en cuenta que el scrapper web sólo permite extraer tweets de carácter público, siendo probable que aquellos que contenían llamados a la acción, fueron twitteados con restricciones de privacidad.

Por otra parte, durante el período de tiempo analizado, abril del año 2016, las movilizaciones se restringieron al escenario chilote. Ello es previo a la introducción, a comienzos del mes de mayo, de Greenpeace de una campaña mediática que involucró uso de hashtags como \#ChiloeResiste. Esta operó en paralelo a los llamados a la movilización por parte de universitarios y ambientalistas en algunas de las principales ciudades del país, como Concepción, Valparaíso, y Santiago, hasta el fin del conflicto. Es importante destacar que se evidencia la relevancia de generar una futura aproximación sobre el detalle del uso de tal hashtag, y del carácter que adquieren los tweets, durante el mes de mayo.

Es preciso considerar el detalle de la frecuencia de tweets sobre la marea roja de Chiloé, durante abril del año 2016, distinción ilustrada en la Figura 4. 


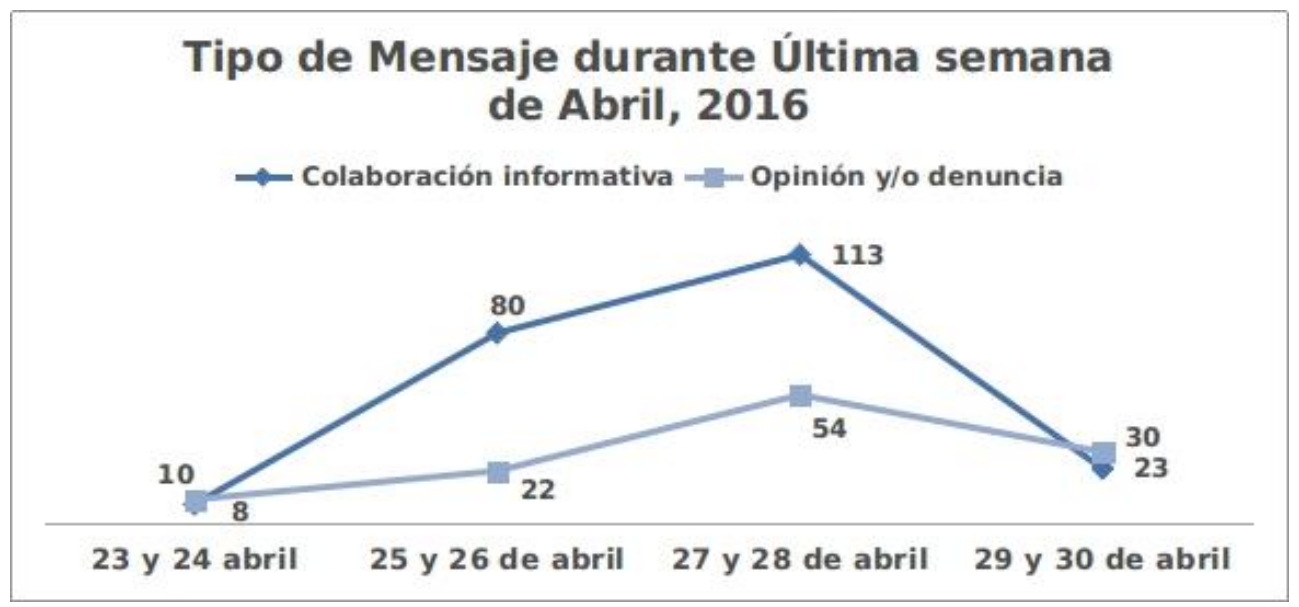

(Figura 4: Publicación de tweets según semana. Elaboración propia).

Se distingue que el $83 \%(n=340 / 409)$ de los tweets son publicados durante la última semana del mes de abril. Entendiendo el bajo volumen de tweets, de todos modos, es imposible omitir el exponencial aumento de publicaciones con las palabras clave de "marea roja" y "Chiloé" durante dicha semana, previo a la aparición de la campaña promovida por Greenpeace.

En el caso de los tweets categorizados como opiniones y/o denuncias, aumentan en 38 veces (de 3 a 116 tweets) respecto de la semana anterior, muy superior a las 5 veces (de 45 a 224 tweets) en que se incrementan las colaboraciones informativas en igual rango de tiempo. Los acontecimientos clave que figuran en tal semana son dos. El primero de ellos, corresponde a la difusión de imágenes sobre una masiva varazón de mariscos, ocurrida en las costas de la isla durante el 25 y 27 de abril del 2016. El segundo, trata sobre la difusión de imágenes sobre los fondos marinos de la isla, repletos de salmones muertos, durante el 29 y 30 de abril del 2016.

Imágenes como esas permitieron argumentar que lo vivido no se trataba de un fenómeno natural, sino producto de la gestión residual de empresas salmoneras del sector. Es posible sostener, en tal sentido, que se despliega una disputa, en la que distintos agentes intentan apropiarse, de acuerdo a sus propósitos, las informaciones circulantes en el espacio configurado en Twitter ${ }^{25}$. Es importante destacar, que estas no figuraron en medios de prensa tradicional en el momento que fueron difundidas, sino hasta días más tarde ${ }^{26}$.

25 Para profundizar sobre la disputa tecnológica, revisar Binimelis, op. cit.

26 En una nota publicada por Canal 13, el día 10 de mayo, se cuestiona la aseveración enunciada por sectores http://www.t13.cl/videos/nacional/expertos-descartan-salmones-muertos-arrojados-al-mar-influyeran-marea-r oja. 


\section{Abril/2016: El uso de Twitter ante la marea roja de Chiloé}

En cierto sentido, es posible constatar una contradicción entre la cobertura que realizan medios de prensa tradicionales y usuarios comunes de Twitter. Tal como sostiene Puente ${ }^{27}$, ciertos medios alternativos, como Twitter, permiten realizar reseñas a hechos, sin necesariamente ceñirse a valores periodísticos que ello implica. Por otra parte, es posible distinguir desde otro punto, que lo realizado por los usuarios comunes de Twitter, corresponde a distintos modos de resistencia ${ }^{28}$. Esta guardaría relación, por ejemplo, con prácticas contra informativas ${ }^{29}$, en tensión con la pauta informativa de medios de prensa tradicionales ${ }^{30}$. Para tales efectos es pertinente reconsiderar el orden de los acontecimientos.

El primer hecho relevante que origina la movilización de los pescadores de Ancud, consiste en la resolución gubernamental de prohibirles extraer y comercializar productos marinos en la zona, durante la primera quincena de abril. Los tweets producidos en tal período corresponden al 5\% $(\mathrm{n}=21 / 409)$ de la muestra analizada.

El segundo hecho, consiste en la declaración de alerta sanitaria sobre la isla, durante la tercera semana del mes de abril. En dicho escenario se publican 48 tweets, que representan el 12\% ( $n=48 / 409)$ del material extraído por el scrapper. Tras la alerta, se decretó el cierre preventivo de todo el borde costero de la isla de Chiloé, lo que generó mayor difusión mediática del acontecimiento. Ello es acompañado de la difusión de imágenes en las que se ilustra el estado de las negociaciones entre autoridades con representantes de pescadores movilizados.

No obstante, en la muestra no se aprecia claramente la difusión de imágenes que tratan sobre las movilizaciones que estos últimos desarrollan en paralelo a las conversaciones. Imágenes y/o vídeos sobre marchas, aglomeraciones, cortes de caminos, barricadas, enfrentamientos con la policía, entre otros puestos en marcha por ellos en dicho contexto, no figuran entre los contenidos que conforman la muestra de estudio. Tal ausencia, puede ser resultado del modo en que se configuró la búsqueda de mensajes mediante el scrapper, limitada al uso de palabras clave sobre tweets de carácter público.

27 Puente, op. cit., 19-32.

28 Para revisar el modo en que el movimiento estudiantil chileno soportó sus repertorios de acción tecnológicamente, revisar Camila Cárdenas, El movimiento estudiantil chileno (2006-2016) y el uso de la web social: Nuevos repertorios de acción e interacción comunicativa, Última Década, 45, 2016, 93-116.

29 Sobre las transformaciones que experimenta la práctica periodística ante la emergencia de medios digitales, revisar Ernesto Picco, El periodismo online en el NOA: Una aproximación a los casos de Santiago del Estero, Salta y Jujuy, Milllcayac, IV, 6, 2017, 305-328.

30 Para profundizar en discusiones sobre la contrainformación, revisar Natalia Vinelli, La televisión desde abajo, historia, alternatividad y periodismo de contrainformación, Cooperativa el Río Suena: El Topo Blindado, 2014. 
Con todo, bajo los parámetros de la presente investigación no es posible determinar si acaso el uso de Twitter contribuyó a la promoción y/o generación de movilizaciones políticas en el escenario estudiado. Sin embargo, y pese a las limitaciones técnicas del estudio, se puede distinguir que no hubo mayor difusión de las acciones desarrolladas por los pescadores movilizados de Chiloé durante abril del 2016.

Lo anterior puede guardar relación con el hecho de que no necesariamente existe un uso masivo de Twitter, en el escenario de estudio. Esto justificaría la realización de futuras aproximaciones basadas en otras plataformas, como Facebook y/o medios digitales alternativos. Ahora bien, también es posible que, simplemente, el modo en que los actores movilizados emplearon repertorios tradicionales offline de organización fue al margen del uso de TICS. Por otra parte, una salida intermedia podría ser que tal uso de TICS se restringió a interacciones privadas. En tal caso, esto justificaría la realización de futuras entrevistas a informantes clave, que permitan dilucidar las especulaciones en la materia.

\section{Discusión: ¿De qué manera contribuye el uso de redes sociales de Internet}

\section{a la movilización social?}

Como se ha mencionado, el conflicto de la marea roja de Chiloé articula aspectos ambientales, sociales, políticos, económicos. Sin embargo, la movilización generada al respecto por los pescadores de Ancud no se centra en discusiones ambientalistas. Denunciaron abusos de la clase política y empresarial chilena, expresadas, por ejemplo, en la implementación de la polémica Ley de Pesca en el país. Igualmente, el supuesto envenenamiento de los mares de la isla, lo entendieron como una jugada estratégica, en términos económicos, orientada a desmantelar la ya precarizada pesca artesanal. Así, los efectos ecológicos que ello implicaría, se entienden como parte de procesos más amplios de acumulación por desposesión ${ }^{31}$.

En lo que al uso de Twitter y al ciclo de movilizaciones ${ }^{32}$ concierne, no es posible establecer una respuesta tajante, principalmente debido a que no es posible determinar cuál fue concretamente su rol. Por ejemplo, en consideración de lo ocurrido en las Primaveras Árabes, diferentes investigadores afirman que las TICS adquirieron un rol fundamental en cuanto a la generación de contenidos, y organización de acciones políticas colectivas.

Sin embargo, en el escenario analizado el uso de Twitter parece estar restringido a la

\footnotetext{
31 Harvey, op. cit., 99-129.

32 Sostenido por pescadores de Chiloé, al que se sumaron ambientalistas y universitarios de las principales ciudades del país.
} 
Jorge Valdebenito, Twitteo, ¿luego resisto? Movilización popular y redes sociales en Chile: La marea roja de Chiloé (2016), Izquierdas, 40, junio 2018:185-201

difusión de información elaborada fundamentalmente por medios de prensa tradicional. En tal sentido, tampoco es posible constatar, a partir de la muestra estudiada, que hubo uso de Twitter por parte de organizaciones territoriales, o de pescadores movilizados, para sus propósitos políticos. Por ejemplo, no se identificó ningún llamado explícito a la acción convocado por alguna organización o activista en el contexto de análisis.

En su lugar, se aprecia que fueron usuarios de distinta índole, los que emplearon Twitter para referirse a lo que acontecía en la isla en cuanto a la marea roja durante abril del 2016. Se trata de medios de prensa tradicionales y usuarios particulares, que compartieron noticias sobre lo ocurrido, pero que tampoco es posible determinar si se trataba o no de habitantes de la isla. Esto último se debe a que ningún tweet de la muestra fue publicado con geo referencia de la ubicación del usuario al momento de su emisión.

¿Cómo se hubiese desarrollado la situación, si las organizaciones de base habrían hecho un uso estratégico, en términos públicos y/o políticos, de TICS? ¿Cómo habría resultado si tal uso se hubiese empleado, por ejemplo, para coordinarse con actores de intereses similares? ¿Qué habría sucedido si tales actores, situados en contextos diferentes, hubieran buscado desarrollar acciones colaborativas de reivindicación política, en espacios transnacionales, hacia agentes como gobiernos, corporaciones, $\mathrm{u}$ organismos internacionales? ¿De qué manera sus repertorios de lucha se habrían coordinado, y qué alcances y limitaciones implicaría el uso de TICS en dicho sentido?

De momento, tales preguntas sólo pueden ser resueltas mediante intuición, abriendo camino a futuras indagaciones que integren otras perspectivas de análisis, sean teóricas o técnico-metodológicas. Aún así, en el marco del presente estudio se ha optado por limitarlo a presentar resultados de una aproximación exploratoria, que más que buscar respuestas, intenta formular preguntas adecuadas para futuras aproximaciones de estudio en la materia.

En consideración de estos elementos, pareciese ser que responder a los objetivos de investigación desde una postura escéptica es lo más adecuado. Por una parte, y de acuerdo a los resultados preliminares esbozados, con sus alcances y limitaciones, el uso de Twitter en el contexto de estudio fue restringido cuantitativamente. Por otra parte, cualitativamente, se distingue un uso informativo por sobre organizativo. A pesar de ello, el uso divulgativo contribuyó, intuitivamente, a la generación de movilizaciones en el resto del país, a partir de la visualización del conflicto ${ }^{33}$.

No obstante, tal conjetura puede constituir objeto de verificación de futuras

33 Desde tal punto, es posible reforzar lo que ciertos autores señalan sobre la apropiación tecnológica que realiza la ciudadanía con fines políticos. Revisar Castells, op. cit., 33-187; Murthy, op. cit., 1-13 y 92-114; y Shirky, op. cit., $1-9$. 
aproximaciones, por ejemplo, mediante el estudio del hashtag de \#ChiloeResiste, introducido por Greenpeace a comienzos de mayo del 2016. De ser así, el desarrollo de agendas digitales para organizaciones de activistas se instalaría como una manera de probabilizar su éxito o al menos visibilizar sus acciones y demandas. Ello facilitaría por ejemplo la apertura a establecer dinámicas de cooperación con actores situados en otros contextos $^{34}$.

Hasta el día de hoy, no existe resolución judicial que materialice la explicación de lo sucedido. Es decir, no hay certeza si acaso se trató de un fenómeno natural de marea roja, o resultado del mal manejo residual de la industria salmonera de la zona, ¿logró entonces, efectivamente, el uso de TICS, como Twitter, generar preocupación en la población sobre lo ocurrido? Con preguntas como estas finaliza la primera parte de la formulación de un problema no resuelto, que requiere de futuras aproximaciones teóricas y prácticas de investigación e intervención. Lo importante de destacar es que ellas debiesen orientarse a generar aprendizajes ciudadanos sobre los mecanismos de reivindicación de demandas políticas a gobiernos y corporaciones no sólo en Chile, sino en América Latina y el mundo entero.

\section{Referencias bibliográficas}

\section{Impresos}

Batthyány, Karina; Cabrera, Mariana; Alsina, Lorena; Bertoni, Marianela; Mascheroni, Paola; Moreira, Natalia; Picasso, Florencia; Ramírez, Jessica y Rojo, Virginia, Metodología de la investigación en Ciencias Sociales: Apuntes para un curso inicial, Universidad de la República, 2011.

Bourdieu, Pierre, Razones prácticas. Sobre la teoría de la acción, Barcelona, Anagrama, 1997.

Bravo, Viviana, Neoliberalismo, protesta popular y transición en Chile, 1973-1989, Política y Cultura 37, 2012, 85-112.

Cabello, Felipe y Godfrey, Henry, Florecimiento de algas nocivas (FANs), ecosistemas marinos y la salud humana en la Patagonia chilena, Revista Chilena de Infectología 33:5, Santiago, 2016, 559-560.

Cáceres, Pablo, Análisis de contenido cualitativo: una alternativa metodológica alcanzable, Revista de la Escuela de Psicología 2, 2003, 53-82.

Cárdenas, Camila, El movimiento estudiantil chileno (2006-2016) y el uso de la web social: Nuevos 
Jorge Valdebenito, Twitteo, ¿luego resisto? Movilización popular y redes sociales en Chile: La marea roja de Chiloé (2016), Izquierdas, 40, junio 2018:185-201

repertorios de acción e interacción comunicativa, Última Década, 45, 2016, 93-116.

Castells, Manuel, Comunicación y poder, Madrid, Alianza Editorial, 2009.

Cortés, Alexis, El movimiento de pobladores chilenos y la población La Victoria: ejemplaridad, movimientos sociales y el derecho a la ciudad, EURE, 2014, 239-260.

Durán, Gonzalo y Kremerman, Marco, Los bajos salarios de Chile. Análisis de la Encuesta CASEN 2015, Ideas para el buen vivir 10, 2017, 1-8.

Dutceac, Anamaria y Bossetta, Michael, A typology of political participation online: How citizens used Twitter to mobilize during the 2015 British general elections, Information, Communication \& Society 20:11, 2017, 1625-1643.

Feenberg, Andrew, Teoría crítica de la tecnología, Revista CTS 2:5, 2005, 109-123.

Fuchs, Christian, Social media: A critical Introduction. Londres, Sage, 2014.

Glaría, Violeta, Sujetos colectivos en búsqueda de sustentabilidad pesquera: relatos de los miembros de una comunidad de pescadores artesanales, V región, Chile, Polis 9:27, 2010, 109-127. Guiloff, Matías, Ley de pesca: Explicando un regalo regulatorio, Anuario de Derecho Público UDP, 2016, 273-296.

Habermas, Jürgen, “The public sphere: An encyclopedia article”, Meenashki Durham, y Douglas Kellner (eds.), Media and Cultural Studies: Keyworks, Wiley-Blackwell, 2012, 75-79.

Harvey, David. El nuevo imperialismo: acumulación por desposesión, Buenos Aires, CLACSO, 2005.

Lotan, Gilad, Graeff, Erhardt, Ananny, Mike, Gaffney, Devin, Pearce, Ian y Boyd, Devin, The Arab Spring! The revolutions were tweeted: Information flows during the 2011 Tunisian and Egyptian revolutions, International Journal of Communication 5, 2011, 1375-1405.

Mosco, Vincent, La economía política de la comunicación: una actualización diez años después, CIC Cuadernos de Información y Comunicación 11, 2006, 57-79.

Murthy, Dhiraj, Twitter. Social Communication in the Twitter Age, Cambridge, Polity Press, 2013.

Picco, Ernesto, El periodismo online en el NOA: Una aproximación a los casos de Santiago del Estero, Salta y Jujuy, Milllcayac, IV, 6, 305-328.

Puente, Soledad, Saavedra, Gonzalo y Grassau, Daniela, Análisis de contenido: Ausencia de valores periodísticos en los medios informativos ciudadanos, Cuadernos de Información 28, 2011, 19-32.

Sábada, Igor, Acción colectiva y movimientos sociales en las redes digitales. Aspectos históricos y metodológicos, ARBOR 188, 2012, 781-794.

Shirky, Clay, The political power of social media, Foreign Affairs 90:1, 2011.

Tilly, Charles y Wood, Lesley, Los movimientos sociales, 1768-2008 desde sus orígenes a Facebook, Barcelona, Crítica, 2010.

Valenzuela, Esteban, Penaglia, Francesco y Basaure, Lía, Acciones colectivas territoriales en Chile 2011-2013: de lo ambiental-reivindicativo al autonomismo regionalista, EURE 42:125, 2016, 225-250.

Vinelli, Natalia, La televisión desde abajo, historia, alternatividad y periodismo de 
contrainformación, Cooperativa el Río Suena: El Topo Blindado, 2014.

Otras fuentes impresas

Arredondo, José y Veliz, Mary, Aspectos teóricos sobre los tipos de muestreos, 2009, Repositorio Institucional de la Universidad de Oriente, recuperado:

http://ri.bib.udo.edu.ve/bitstream/123456789/594/1/TESIS_MVyJA--\%5B00550\%5D--\%28tc\%29.p df

\section{Referencias electrónicas}

Binimelis, Helder, Disputas tecnológicas y diversidad contextual: El poder tecnológico más allá del capitalismo, Primavera Hacker 2016, 2016, recuperado de: https://www.youtube.com/watch?v=59ulsuz-z6M\&t=7s

Canal 13, Expertos descartan que salmones muertos arrojados al mar influyeran en Marea Roja, recuperado de:

http://www.t13.cl/videos/nacional/expertos-descartan-salmones-muertos-arrojados-al-mar-influyera n-marea-roja

Greenpeace, Reporte crisis social ambiental en Chiloé: Resumen ejecutivo, 2016, recuperado de: https://www.salmonexpert.cl/wp-content/uploads/2016/09/322995006-Informe-de-Greenpeace-pormarea-roja-en-Chiloe.pdf

HispanTV, Chiloé: La vía chilena al subdesarrollo, 2016, recuperado de: https://www.youtube.com/watch?v=-I0tElnLyd8 